Research Paper

\title{
The Clinical Pattern of Knee Osteoarthritis in Jordan: A Hospital Based Study
}

\author{
Ziad M. Hawamdeh ${ }^{1,}$, Jihad M. Al-Ajlouni² \\ 1. Faculty of Rehabilitation Sciences - The University of Jordan, Amman, Jordan. \\ 2. Faculty of Medicine- The University of Jordan, Amman, Jordan.
}

$\triangle$ Corresponding author: Ziad M. Hawamdeh, Faculty of Rehabilitation Sciences, the University of Jordan, Amman, Jordan. Phone: 00962777457263. Fax: 009625300252 email: z.hawamdeh@ju.edu.jo or ziadnet2004@yahoo.co.uk.

() Ivyspring International Publisher. This is an open-access article distributed under the terms of the Creative Commons License (http://creativecommons.org/ licenses/by-nc-nd/3.0/). Reproduction is permitted for personal, noncommercial use, provided that the article is in whole, unmodified, and properly cited.

Received: 2012.08.3I; Accepted: 2013.02.22; Published: 2013.04.25

\begin{abstract}
Background: Different clinical profiles of knee osteoarthritis (KOA) have been reported in the literature. The aim of this investigation was to describe the clinical patterns of KOA in an ethnically distinct and homogenous population that has not been widely reported. Patients with KOA were seen in outpatient rehabilitation and orthopedic clinic of Jordan University Hospital (JUH), to determine any possible association between age, BMI, radiographic severity, and pain severity.

Methods: Patients diagnosed with KOA attending an outpatient rehabilitation clinic at JUH were studied to describe their clinical characteristics. They were included based on criteria developed by the American College of Rheumatology. Detailed histories, clinical examinations and X-rays, and anthropometric data were obtained. Data analysis focused on descriptive statistics and correlations among demographic and clinical characteristics.

Results: The study included 214 patients with a mean age of 55.3 years (range $=30-84$ years). The mean BMI was 29.5 5.6. We found a significant moderate positive correlation between age and radiographic severity of KOA $(0.435 ; \mathrm{p}<.00 \mathrm{I})$ and pain severity $(0.383 ; \mathrm{p} .<.00 \mathrm{I})$. There was also a significant weak positive correlation between BMI, radiographic severity of $K O A(0.242, p<.05)$, and pain severity $(0.266$, p. <. 01$)$.

Conclusions: We concluded that in this hospital-based cohort study in Jordan, the clinical pattern of KOA is comparable to Western cultures. However, the combination of BMI and mechanical loading during everyday activities that include different religious and cultural habits and may help explain the high level of radiographic severity in our sample.
\end{abstract}

Key words: Clinical pattern, knee osteoarthritis, culture, Jordan.

\section{INTRODUCTION}

Osteoarthritis (OA) is a chronic multifactorial disease characterized by progressive joint degeneration accompanied by subchondral bone sclerosis which can lead to the formation of bone cysts and marginal osteophytes ${ }^{1}$. Besides these intrinsic changes of the joints, other signs such as decreased knee flexibility, pain and joint effusion, crepitus, deformities, and loss of function are often present ${ }^{2}$.It is a leading musculoskeletal cause of disability in elderly persons all over the world and a major cause of physical limitations and reduced quality of life 1,2 . In the United States (US), ${ }^{3}$ and according to the World Health Organization, it is estimated that $10 \%$ of the world population over 60 years of age has symptomatic knee OA, 4,5 and that $12 \%$ of adults aged 65 years and older have symptomatic knee OA.

The prevalence of knee OA increases with age and is more common in women than in men ${ }^{6}$.The ex- 
act etiology of knee OA remains unclear, but it is frequently associated with repetitive microtraumas, previous knee surgery, metabolic or endocrinological factors, heredity, obesity and joint overload 7,8,9. Radiographic findings include joint space narrowing, osteophyte formation, subchondral sclerosis and cysts $^{3}$. However, radiological findings don't always correlate with patients' knee symptoms ${ }^{10}$. The disease has a progressive impact upon activities of daily living, ultimately leading to a progressive loss of functional independence and deterioration of quality of life. Current clinical guidelines recommend non-pharmacological strategies as the first line management of OA symptoms 8,11. Interventions have typically focused on symptomatic relief and improvement of functional status 9,12 as well as lifestyle modification, weight reduction, drugs, surgery, and rehabilitation interventions such as exercises and physical agents ${ }^{13-16}$.

Although knee OA occurs all over the world, the pattern of disease varies among populations 17-20. Studies describing the clinical pattern of knee OA in Jordanian patients are lacking. Jordan is primarily an agrarian society without the advantages of sophisticated agrarian technology, and the majority of populations are Arab Muslim who has their cultural habits that make them different from western countries. Muslims pray on their knees five times a day. The Jordanian peoples have cultural habits that include sitting in a kneeling position for long periods of time during the day. Peoples also tend to delay decisions regarding surgical interventions and many of them tend to delay surgery and this may aggravate their medical condition. Because of these factors, we anticipated that the clinical pattern of KOA could be different and the severity of KOA would be greater than that of the Western world. The aim of the present study was to describe the pattern of KOA in terms of age, gender, BMI, radiological severity, pain severity, and joint involvement and to investigate any association among age, BMI, radiological severity, and pain severity of a cross-section of KOA patients seen in outpatient rehabilitation and orthopedic clinics of Jordan University Hospital (JUH).

\section{METHODS}

\section{Study population}

This cross sectional study was conducted in the Outpatient Rehabilitation and orthopedic Department of JUH. Eligible participants were patients with KOA $\geq 30$ years old who were referred from various outpatient departments and did not have another condition that might have interfered with the assessment of
KOA. The study period was between May 2011 and November 2011. Knees with radiographic evidence of inflammatory arthritis were excluded in the analysis. Individuals with any evidence of secondary OA, previous fractures involving knee joints or injuries of the knee (ligament or cartilage injuries) and those with neurological or inflammatory conditions were excluded. Ethical committee approval at JUH was obtained, and once the rationale and procedures for the study were explained to potential subjects, their consent to participate in the study was sought and obtained. Detailed histories including demographic data, pain characteristics, use of assistive devices and patient occupation were obtained. Clinical examinations, $\mathrm{X}$-rays, and anthropometric data were collected during a single clinic visit.

\section{Diagnosis and classification}

The patients were selected according to the clinical criteria developed by the American College of Rheumatology (ACR) ${ }^{21}$ which is as follows:

1. Knee pain for most days of prior month.

2. Age $>50$ years.

3. Morning stiffness of the knee $<30$ minutes.

4. Crepitus on active joint motion.

5 . Bony tenderness.

6. Bony enlargement.

7. No palpable warmth

OA knee was considered to be present when: 1 , $2,3,4$, or $1,2,6$ or $1,4,6$ were found.

\section{Height and body mass index (BMI)}

Height measurements were taken with subjects standing erect with bare-feet and heels touching and eyes directed straight ahead. A meter rule was placed on a level floor at the zero mark. A pointer placed directly horizontal to the vertex of the head with one end pointed to the mark in the meter rule revealed the reading of the height to the nearest $0.1 \mathrm{~cm}$.

Body mass indices (BMI) were calculated for each of the subjects. Body mass index is defined as the individual's body weight divided by the square of his or her height. The formulae universally used in medicine produces a unit of measure of $\mathrm{kg} / \mathrm{m}^{2}{ }^{2}{ }^{22}$

\section{Grading of radiographic KOA}

The severity of KOA was determined by a specialized physiatrist according to patient history, examinations and radiologic evaluation of the knees using the criteria of Kellgren and Lawrence (K \& L, 1957) ${ }^{23}$. Radiographic classification of KOA severity was based on the $\mathrm{K} \& \mathrm{~L}$ scale with patients having a score of 2 classified as mild KOA, a score of 3 classi- 
fied as moderate $\mathrm{KOA}$, and a score of 4 classified as severe KOA.

\section{Pain severity}

The severity of pain was measured using a visual analogue scale (VAS) for knee pain in the previous week. It represents the severity dimensions by a $10 \mathrm{~cm}$ plain line with two anchor points of no pain and worst pain I ever felt. The patient is requested to draw a line at the point that best describes his or her pain level. It is the most widely used scale in the assessment of pain in the clinical setting and has been reported to be sensitive and reliable. ${ }^{24}$ The cut points for severity were determined as ( 1 to $3=$ mild pain, $\geq 4$ to 7 for moderate pain, and $\geq 8$ to 10 severe pain) ${ }^{25}$.

Table I. Baseline characteristics of patients $(n=2 \mid 4)$.

\begin{tabular}{|c|c|}
\hline Patient Characteristics & Mean (SD)/ n (\%) \\
\hline Age in years (SD) & $55.27(16.1)$ \\
\hline \multicolumn{2}{|l|}{ Gender } \\
\hline Male, n (\%) & $96(44.8)$ \\
\hline Female, n (\%) & $118(55.2)$ \\
\hline Height in cm (SD) & $163.8(9.1)$ \\
\hline Weight in kg (SD) & $79.0(12.8)$ \\
\hline Body Mass Index (kg/m²) (SD) & $29.5(5.6)$ \\
\hline Males & $28.5(3.9)$ \\
\hline Females & $30.3(6.7)$ \\
\hline \multicolumn{2}{|l|}{ Affected Side } \\
\hline Left, $\mathrm{n}(\%)$ & $50(31.0 \%)$ \\
\hline Right, $\mathrm{n}(\%)$ & $68(69.0 \%)$ \\
\hline Bilateral & $96(44.8 \%)$ \\
\hline \multicolumn{2}{|l|}{ Occupation } \\
\hline Housewives & $80(37.3 \%)$ \\
\hline government employee & $70(32.7 \%)$ \\
\hline retired & $44(20.5 \%)$ \\
\hline Private employees and others & $20(9.1 \%)$ \\
\hline Mean duration of symptoms & $18.25 \pm 23.85$ months \\
\hline Use of assistive devices (cane or walker) & $25(11.6 \%)$ \\
\hline \multicolumn{2}{|l|}{ Type of pain } \\
\hline Intermittent in nature & $140(65.4 \%)$ \\
\hline Constant in nature & $74(34.6 \%)$ \\
\hline $\begin{array}{l}\text { Presence of morning stiffness(less than } 1 \\
\text { hour }\end{array}$ & $44(20.6 \%)$ \\
\hline
\end{tabular}

\section{Statistical analyses}

Descriptive statistics and frequency distributions were generated for the patients' demographic and disease related characteristics. Data are presented as means and standard deviations (SD) or frequencies and percentages. Correlations between age, BMI and the radiographic severity of KOA and severity of pain were assessed using Spearman's correlation coefficient because not all data were normally distributed. The correlation was defined as weak if the coefficient was less than 0.3 , moderate if it was between 0.3 and 0.69 , and strong if it was greater than 0.7. Data were analyzed using SPSS version 15.0.

\section{RESULTS}

A total of 232 patients with KOA were screened and found eligible to participate in the study. Eighteen patients dropped out because they did not give consent to participate, leaving 214 patients who were evaluated and included in the study.

\section{Clinical characteristics}

The mean BMI was 29.5 $\pm 5.63(28.54 \pm 3.97$ for males and $30.31 \pm 6.65$ for females). Those with mild radiographic KOA had an average BMI of 26.29, those with moderate radiographic KOA had an average BMI of 29.04 and those with severe radiographic KOA have an average BMI of 30.57. Twenty-eight patients $(13 \%)$ had mild radiographic KOA (16 males, 12 females), 72 patients $(33.6 \%)$ had moderate radiographic KOA (38 males, 34 females) and 114 (53\%) had severe radiographic KOA (44 males, 70 females) (Fig. 1). Thirty-six patients $(16.8 \%)$ had mild pain (20 males, 16 females), 82 patients $(38.3 \%)$ had moderate pain (44 males, 38 females), and 96 patients (44.8\%) had severe pain (34 males, 62 females) (Fig 2).

Table 2 includes spearman correlation coefficients for age, BMI radiographic severity of KOA and pain intensity. Moderate, but significant, positive correlations were found between age, radiographic severity of KOA and pain severity. A significant, but weak positive correlation was found between BMI, radiographic severity and pain severity.

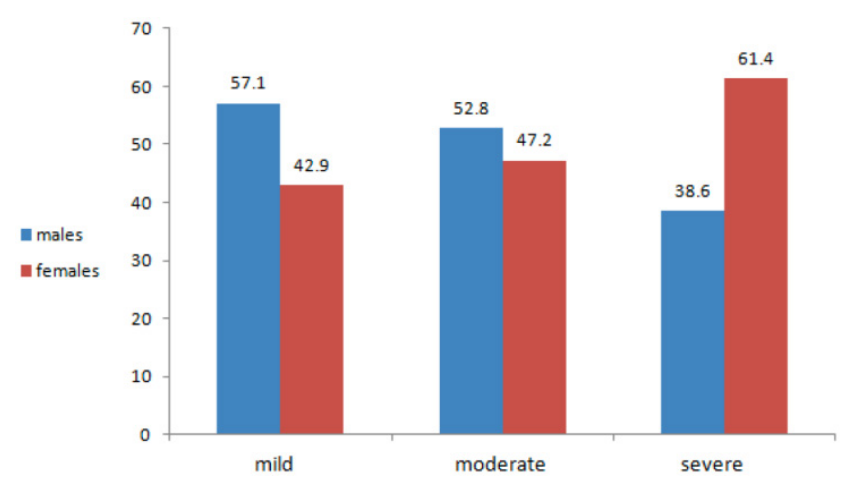

Fig I. Percentage distribution of radiographic severity of KOA, by gender. 


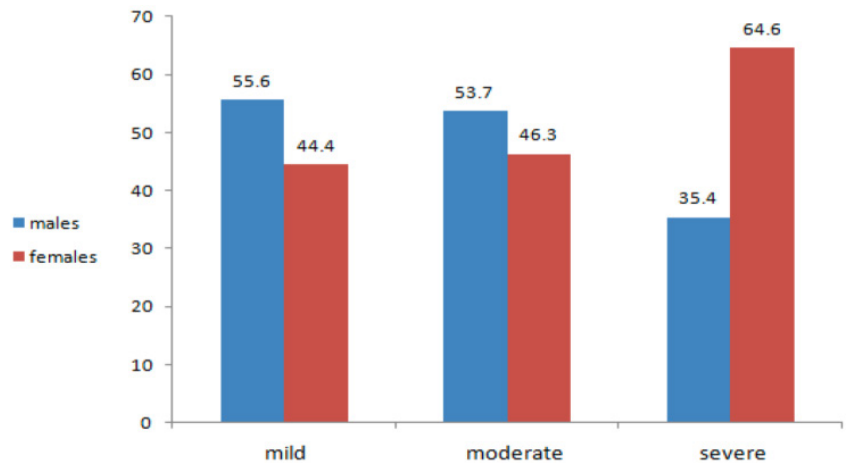

Fig 2. Percentage distribution of pain severity, by gender.

Table 2. Association between demographic and clinic characteristics.

\begin{tabular}{lllll}
\hline & Age & BMI & $\begin{array}{l}\text { Radiographic } \\
\text { Severity }\end{array}$ \\
\hline Age & ----- & ---- & $0.435^{* * *}$ & $0.383^{* * *}$ \\
BMI & & ----- & $0.242^{*}$ & $0.266^{* *}$ \\
Radiographic se- & & & ----- & $0.412^{* *}$ \\
verity & & & \\
Pain severity & & & & ---- \\
\hline${ }^{*} \mathrm{p}<.05 ;{ }^{* *} \mathrm{p}<.01 ;{ }^{* * *} \mathrm{p}<.001$. & &
\end{tabular}

\section{DISCUSSION}

Knee OA is one of the most common joint diseases worldwide, but the clinical pattern of knee OA may be different in different populations due to lifestyle and everyday activities. The purpose of the present study was to examine the clinical characteristics of patients with KOA in an ethnically distinct and homogenous population that has not been widely reported and to determine if our patients varied from those in other cultures. Specifically, in this cross-sectional study we described the demographic and clinical characteristics of our sample, and the association among age, BMI, radiographic severity of $\mathrm{KOA}$, and pain severity in Jordanian patients attending an outpatient rehabilitation department at JUH.

Our results showed that out of 214 patients with KOA, 118 (55.2\%) were females and 96 (44.8\%) were males. the female to male ratio was 1.22: 1 . of them $44.8 \%$ had bilateral knee OA. The sex distribution of OA patients in this study indicates a female predominance and corresponds with the findings of previous studies $17-20,26$. A reason for this predominance can be attributed to the role of muscle mass as it's generally reduced in women compared to men, and the measure of weight or BMI alone does not necessarily quantitate the contribution of muscle vs. fat. Another explanation may be related to size differences in men and women as women generally having smaller joints and lesser absolute amount of cartilage which may expose them to more joint problems.

Most of the patients in our study were in the age group of 40 to 59 years. There was a significant positive association between age, radiographic severity, and pain severity. This finding supports the fact that $\mathrm{OA}$ is a common health problem in middle and old age and this is consistent with previous studies 27,28 . Age is considered as a strong risk factor for $\mathrm{KOA}$, but the underlying mechanism remains obscure $29,30$. Whereas tensile stiffness of knee articular cartilage and proteoglycan content decrease with age 30,31,32, advanced glycation end products and cartilage turnover markers increase with age $33,34,35$. These biomechanical and biochemical changes in articular cartilage may have a role in age related OA, but age related morphological alterations in articular cartilage and subchondral bone are potential further explanations for OA.

Obesity and overweight have long been recognized as potent risk factors for OA, especially OA of the knee $6,26,36$. This was also reflected in our study with the overall mean BMI being $29.5 \pm 5.63$, as well as the consistent increase in radiologic severity of KOA associated with increases in BMI. This association is also consistent with numerous previous studies which have shown a positive association between BMI and $\mathrm{OA}$ in weight-bearing joints, such as the hip, knee, and foot 9,26,37-41. Increased mechanical loading on the joint is probably the main, but not only, mechanism by which obesity can lead to knee OA. Overloading of the knee can lead to synovial joint breakdown and failure of ligamentous and other structural support. Because the patients in the study were Arab Muslim who have their different religious and cultural and daily habits compared to western population in addition to the tendency of people to delay decisions regarding surgery, the combination of elevated BMI and mechanical loading could help to explain why 73 percent of our patients' radiographic scores were in the severe range, compared to other studies. ${ }^{20}$

Our findings that greater pain severity was significantly correlated with a higher BMI is similar to the findings of other studies ${ }^{42}$ including Cimmino et al. ${ }^{43}$, who noted a significant relationship between pain and $\mathrm{BMI} \geq 30 \mathrm{~kg} / \mathrm{m}^{2}$ (odds ratio $=1.52 ; 95 \%$ confidence interval, 1.42 to 1.61) among people with different forms of OA. Likewise, occupational demands such as kneeling, squatting, climbing stairs, and lifting and carrying heavy loads have been associated with $\mathrm{KOA}^{44-48}$. The majority of our patients $(37.3 \%)$ were housewives, and Dahaghin et al. ${ }^{49}$ found that the 
physical demands of caring for a home and family put housewives at greater risk of developing KOA. Another issue to be considered is that most of older Jordanian females are housewives and this may have biased the findings of our study. Cultural factors may also play a role as our cultural habits include sitting in a kneeling position for long periods of time during the day, and this is more common in elderly people and peoples living in rural areas. Religious daily activities such as praying also includes kneeling, knee bending and repeated squatting five times a day.

As with all studies, our study had limitations. Our sample may not be representative of all KOA patients across Jordan. Our findings are based a cross-section of patients who have elected to seek medical care at one hospital, and therefore results may not be generalizable to the community.

\section{CONCLUSION}

Although our sample consisted of an ethnically distinct and homogenous population in Jordan, the relationships among demographic and clinical characteristics mirror those of Western cultures. However, the radiographic severity of our sample was considerably greater than that reported in other studies. BMI and mechanical loading during activities of daily living, may explain the difference. Future studies could include hospitals in more rural regions, as well as clinics in the community.

\section{Conflict of Interest}

The authors report no conflicts of interest. The authors alone are responsible for the content and writing of the paper.

\section{References}

1. Buckwalter JA, Lane NE. Athletics and osteoarthritis. Am J Sports Med 1997; 25:873-81.

2. Gupta KB, Duryea J, Weissman BN. Radiographic evaluation of osteoarthritis. Radiol Clin North Am 2004; 42:11-41.

3. Felson DT, Naimark A, Anderson J, Kazis L, Castelli W, Meenan RF. The prevalence of knee osteoarthritis in the elderly. The Framingham Osteoarthritis Study. Arthritis Rheum 1987; 30:914-18.

4. [Internet] Symmons D, Mathers C, Pfleger B. Global burden of osteoarthritis in the year 2000. http://www.who.int/healthinfo/statestics/bod osteaarthritis pdf.

5. [Internet] United States Census Bureau. http://www.census.gov/ipc/www/idb/worldpop.html.

6. Dieppe PA. Clinical features and diagnostic problems in osteoarthritis. In: Klipple JH, Dippe PA. eds. Practical Rheumatology. London: Mosby; 1995:141-56.

7. Felson DT. Epidemiology of osteoarthritis. In: Brandt KD, Doherty. M, Lohmander S. eds. Osteoarthritis. 2nd ed. Oxford: Oxford University Press; 2003:9-16.

8. Jordan KM, Arden NK, Doherty M, Jordan KM, Arden NK, Doherty M, Bannwarth B, Bijlsma JW, Dieppe P, Gunther K, Hauselmann H, Herrero-Beaumont G, Kaklamanis P, Lohmander S, Leeb B, Lequesne M, Mazieres B, Martin-Mola E, Pavelka K, Pendleton A, Punzi L, Serni U, Swoboda B, Verbruggen G, Zimmerman-Gorska I, Dougados M. EULAR recommendations 2003-an evidence based approach to the management of knee osteoarthritis: report of a task force of the standing com- mittee for international clinical studies including therapeutic trials (ESCISIT). Ann Rheum Dis 2003; 62:1145-55.

9. Oliveria SA, Felson DT, Reed JI, Cirillo PA, Walker AM. Incidence of symptomatic hand, hip, and knee osteoarthritis among patients in a health maintenance organization. Arthritis Rheum 1995; 38:1134-41.

10. Kellgren JH, Lawrence JS. Radiological assessment of osteoarthrosis. Ann Rheum Dis 1957;16:494-502.

11. American College of Rheumatology. Recommendations for the medical management of osteoarthritis of the hip and knee 2000 update. Arthritis Rheum 2000; 43:1905-15.

12. Zhang W, Moskovitz RW, Nuki G Abramson S, Altman RD, Arden N, Bierma-Zeinstra S, Brandt KD, Croft P, Doherty M, Dougados M, Hochberg M, Hunter DJ, Kwoh K, Lohmander LS, Tugwell P. OARSI recommendations for the management of hip and knee osteoarthritis, part II: OARSI evidence-based, expert consensus guidelines. Osteoarthritis Cartilage 2008; 16:137-162.

13. Bjordal JM, Johnson MI, Lopes-Martins RA, Bogen B, Chow R, Ljunggren AE. (2007) Short-term efficacy of physical interventions in osteoarthritic knee pain. A systematic review and meta-analysis of randomised placebo-controlled trials. BMC Musculoskelet Disord 2007; 22: 8-51.

14. Cetin N, Aytar A, Atalay A, Akman MN. Comparing hot pack, short-wave diathermy, ultrasound, and TENS on isokinetic strength, pain, and functional status of women with osteoarthritic knees: a single-blind, randomized, controlled trial. Am J Phys Med Rehabil 2008; 87:443-451.

15. Van Nguyen JP, Marks R. Pulsed electromagnetic fields for treating osteoarthritis. Physiotherapy 2002; 88:458-470.

16. Tuzun EH, Otman S, Kirdi N. Comparison of different methods of pulsed shortwave diathermy in knee osteoarthritis. The Pain Clinic 2003; 15:421-427.

17. Adebajo AO. Patterns of osteoarthritis in the university college Hospital Ibadan Nigeria. Ann Rheum Dis 1991;50:20-22.

18. Eti E, Kouko H, Daboiko JC, Quali B, Quattara B, Gabla KA, Koukou N. Epidemiology and features of knee Osteoarthritis in the Ivory Coast. Rev du Rhumatisme. 1998; 65:770-76.

19. Malaviya AN, Shehab D, Bhargava S, Al-Jarallah K, Al-Awadi A., Sharma P N, Al-Ghuriear S, Al-Shugayer A. Characteristics of osteoarthritis among Kuwaitis: A hospital-based study. Clin Rheumatol. 1998;17:210-13.

20. Snijders GF, den Broeder AA, van Riel PLCM, Straten VHHP, de Man FHR, van den Hoogen FHJ, van den Ende CHM, on behalf of the NOAC study group. Evidence-based tailored conservative treatment of knee and hip osteoarthritis: between knowing and doing. Scand J Rheumatol $2011 ; 40: 225-31$.

21. Altman R, Asch E, Bloch D, Bole G, Borenstein D, Brandt K, Christy W, Cooke TD, Greenwald R, Hochberg M, et al. Development of criteria for the classification of osteoarthritis: classification of osteoarthritis of the knee. Arthritis Rheum 1986; 29:1039-49.

22. Eknoyan, G. "Adolphe Quetelet (1796-1874) - the average man and indices of obesity". Nephrol Dial Transplant 2008;23:47-51.

23. Kelloren JH, Lawrence JS. Atlas of standard radiographs: The epidemiology of chronic rheumatism Vo 12. Oxford: Blackwell Scientific. 1963.

24. Bellamy N. Osteoarthritis clinical trials: candidate variables and clinimetric properties. J Rheumatol 1997;24:768-78.

25. Kapstad H, Hanestad BR, Langeland N, Rustøen T, Stavem K. Cut points for mild, moderate and severe pain in patients with osteoarthritis of the hip or knee ready for joint replacement surgery. BMC Musculoskeletal Disord 2008; 9:55.

26. Felson DT. The epidemiology of knee osteoarthritis: results from the Framingham Osteoarthritis Study. Semin Arthritis Rheum 1990;20:42-50.

27. Altman, RD. Criteria for classification of clinical osteoarthritis. J Rheumatol 1991;18 (Suppl 27):10-12.

28. Dequeker, J; Dieppe, PA. Disorders of bone cartilage and connective tissue. In: Klippel JH, Dieppe PA, eds. Rheumatology, 2nd ed. London: Mosby;1998: 24-25.

29. Felson DT, Lawrence RC, Dieppe PA, Hirsch R, Helmick CG, Jordan JM, Kington RS, Lane NE, Nevitt MC, Zhang Y, Sowers M, McAlindon T, Spector TD, Poole AR, Yanovski SZ, Ateshian G, Sharma L, Buckwalter JA, Brandt KD, Fries JF. Osteoarthritis: new insights. Part 1: the disease and its risk factors. Ann Intern Med 2000;133:635-46.

30. Kempson GE. Age-related changes in the tensile properties of human articular cartilage: a comparative study between the femoral head of the hip joint and the talus of the ankle joint. Biochim Biophys Acta 1991;31:223-30.

31. Bank RA, Bayliss MT, Lafeber FP, Maroudas A, Tekoppele JM. Ageing and zonal variation in post-translational modification of collagen in normal human articular cartilage: the age-related increase in 
non-enzymatic glycation affects biomechanical properties of cartilage. Biochem J 1998; 30:345-51.

32. Brandt KD, Fife RS. Ageing in relation to the pathogenesis of osteoarthritis. Clin Rheum Dis 1986; 12:117-30.

33. Verzijl N, Bank RA, TeKoppele JM, DeGroot J. Ageing and osteoarthritis: a different perspective. Curr Opin Rheumatol 2003; 15:616-22.

34. Mouritzen U, Christgau S, Lehmann HJ, Tanko LB, Christiansen C. Cartilage turnover assessed with a newly developed assay measuring collagen type II degradation products: influence of age, sex, menopause, hormone replacement therapy, and body mass index. Ann Rheum Dis 2003; 62:332-36

35. Jordan JM, Luta G, Stabler T, Renner JB, Dragomir AD, Vilim V, Hochberg MC, Helmick CG, Kraus VB. Ethnic and sex differences in serum levels of cartilage oligomeric matrix protein: the Johnston County Osteoarthritis Project. Arthritis Rheum 2003; 48:675-81.

36. Powell A, Teichtahl AJ, Wluka AE, Cicuttini FM. Obesity: a preventable risk factor for large joint osteoarthritis which may act through biomechanical factors. Br J Sports Med 2005; 39:4-5.

37. Cooper C, Inskip H, Croft P, Campbell L, Smith G, McLaren M, Coggon D. Individual risk factors for hip osteoarthritis: obesity, hip injury, and physical activity. Am J Epidemiol 1998;147:516-522.

38. Felson DT, Anderson JJ, Naimark A, Walker AM, Meenan RF. Obesity and knee osteoarthritis. The Framingham Study. Ann Intern Med 1988; 109:18-24

39. Kellgren JH, Lawrence JS. Osteo-arthrosis and disk degeneration in an urban population. Ann Rheum Dis 1958;17:388-97.

40. Leveille SG, Guralnik JM, Ferrucci L, Hirsch R, Simonsick E, Hochberg MC. Foot pain and disability in older women. Am J Epidemiol 1998;148:657-65.

41. Spector TD, Hart DJ, Doyle DV. Incidence and progression of osteoarthritis in women with unilateral knee disease in the general population: the effect of obesity. Ann Rheum Dis 1994; 53:565-568.

42. Creamer, P, Lethbridge-Cejku, M, Hochberg, MC. Determinants of pain severity in knee osteoarthritis: effect of demographic and psychosocial variables using 3 pain measures. J Rheumatol 1999; 26:1785-92.

43. Cimmino MA, Sarzi-Puttini P, Scarpa R, Caporali R, Parazzini F, Zaninelli A, Marcolongo R. Clinical presentation of osteoarthritis in general practice: determinants of pain in Italian patients in the AMICA study. Semin Arthritis Rheum 2005; 35(Suppl 1):17-23.

44. Klußmann A, Gebhardt H, Liebers F, von Engelhardt LV, Dávid A, Bouillon B, Rieger MA. Individual and occupational risk factors for knee osteoarthritis - Study protocol of a case control study. BMC Musculoskelet Disord 2008; 9:26.

45. Anderson JJ, Felson DT. Factors associated with osteoarthritis of the knee in the First National Health and Nutrition Examination Survey (NHANES I). Evidence for an association with overweight, race, and physical demands of work. Am J Epidemiol 1988; 128:179-89.

46. Felson DT, Hannan MT, Naimark A, Berkeley J, Gordon G, Wilson PW, Anderson J. Occupational physical demands, knee bending and knee osteoarthritis: results from the Framingham Study. J Rheumatol 1991; 18:1587-92.

47. Zhang Y, Hunter DJ, Nevitt MC, Xu L, Niu J, Lui LY, Yu W, Aliabadi P, Felson DT (2004) Association of squatting with increased prevalence of radiographic tibiofemoral knee osteoarthritis: the Beijing Osteoarthritis Study. Arthritis Rheum 2004; 504:1187-92

48. Coggon D, Croft P, Kellingray S, Barrett D, McLaren M, Cooper C. 2000 Occupational physical activities and osteoarthritis of the knee. Arthritis Rheum 2000;43:1443-49.

49. Dahaghin S, Tehrani-Banihashemi S A, Faezi S T, Jamshidi A R, Davatchi F. Squatting, sitting on the floor, or cycling: Are life-long daily activities risk factors for clinical knee osteoarthritis? Stage III results of a community-based study. Arthritis Rheum 2009;6:1337-42. 